\title{
Demand and Burden of Dental Care in Canadian Households
}

\author{
Mustafa Andkhoie ${ }^{1}$, Eleonora Pandovska-Pelivanova ${ }^{1}$, Simeon Emmanuel $^{1}$, Faisal Lateef ${ }^{1}$, Michael Szafron ${ }^{1} \&$ \\ Marwa Ezzat Farag ${ }^{1}$ \\ ${ }^{1}$ School of Public Health, University of Saskatchewan, Saskatoon, SK, Canada \\ Correspondence: Marwa Ezzat Farag, School of Public Health, University of Saskatchewan, Saskatoon, SK, \\ S7N5E5, Canada. Tel: 1-306-966-5959. E-mail: marwa.farag@usask.ca
}

Received: June 8, 2014

Accepted: June 22, 2014

Online Published: August 25, 2014

doi:10.5539/ijef.v6n9p73

URL: http://dx.doi.org/10.5539/ijef.v6n9p73

\begin{abstract}
This paper examines factors associated with dental care spending in Canada employing through three models; the first model estimates the income elasticity of demand for dental care and the other two models estimate the share of total household income spent on dental care. The income elasticity of Canadian households in 2009 with respect to out-of-pocket dental care spending was 0.146 (p-value $<0.001$ ). The lowest income quintile had the highest odds for spending $\$ 0$ on dental care, which could indicate not using dental care or having full coverage. However, when these households did spend on dental care, they were most likely to have a higher burden of dental expenditure as a share of household income. Having private health insurance is associated with an increase in the demand for dental care but it also reduces the likelihood of the households having a higher burden of dental expenditures as a share of household income. Older adults (65 years or older), compared to young adults (aged 29 years or less) are most likely to spend on dental care and most likely to be in the higher burden category (RRR 2.55 compared to lower burden category, p-value $<0.001$ ). This study found significant interprovincial variation; Yukon, Northwest Territories, Nunavut and Alberta households were found to spend the most on dental care when compared to the rest of the provinces.
\end{abstract}

Keywords: Canada, demand, dental care, elasticity, health, income, insurance, oral, out of pocket

\section{Introduction}

The oral health care system in Canada is mostly privately operated, where the majority of dental services are owned and operated by dental professionals in solo private practices (Canadian Dental Association, 2010). Most Canadians pay for oral health services through work-related insurance or through private means commonly referred to as out-of-pocket (OOP) expenditures (Health Canada, 2010). The Canadian Institute for Health Information (CIHI, 2012) found that Canadians spent $\$ 12.1$ billion on private dental care in 2010, of which $\$ 5.6$ billion was paid OOP and $\$ 6.5$ billon was paid by private insurance. The resulting total per capita health expenditure on dental services was $\$ 354$ per person in 2010 (CIHI, 2012). Thus Canadians spend a substantial amount of money on private dental care through either means of private insurance or payment out of pocket. In addition, in 2011, the Canadian Centre for Policy Alternatives (CCPA) found that the public sector expenditure on dental care represents a small proportion of the overall dental services in Canada, that is approximately $5 \%$ of all dental expenditures in 2009 (CCPA, 2011).

According to the CIHI (2012), the second-largest (right behind drug expenditures) share of private-sector health care spending in 2010 was dental care, showing an annual growth of $5.9 \%$ since 2000 . At the same time, the growth in the public sector dental care expenditure varied provincially, from a low of $1.2 \%$ in Ontario ( $\$ 6$ per person) to a high of $77.6 \%$ in Nunavut (almost $\$ 350$ a person) (CCPA, 2011). Over the same period, the average public health spending increased by $4.3 \%$ ranging from a low of $-2.1 \%$ in Northwest territories (NWT) to a high of $10.1 \%$ in Alberta $(\mathrm{AB})$. These figures are important, as we ought to ask what type of households in Canada bare the largest burden of dental expenses as a share of their total income.

Employment-based insurance and out-of-pocket expenditures are the main sources of financing in Canada's dental care market (Health Canada, 2010; Millar \& Locker, 1999). Evidence has shown that having dental insurance coverage is one of the main factors that determine whether or not Canadians seek dental care. The Oral Health Component of the Canadian Health Measures Survey (CHMS) found that $62 \%$ of Canadians have private dental insurance (usually an employee benefit), $6 \%$ have public insurance, and $32 \%$ have no dental insurance 
(Health Canada, 2010; Millar \& Locker, 1999). The CHMS also reports that lower-income Canadian families consistently have worse outcomes in terms of oral health, untreated disease, lower rates of visiting a dentist, higher proportions of avoiding dental visits and declining recommended care because of financial barriers to accessing dental care (Health Canada, 2010; CCPA, 2011).

The purpose of this paper is to examine the financial burden associated with out-of-pocket dental spending in Canada in order to investigate inequities requiring policy interventions. The paper also explores whether different provinces in Canada have managed to achieve significantly different levels of financial protection for its citizens or not. The reason for exploring interprovincial variation is to learn from more successful provinces. The paper tries to unveil possible explanations for variations in household dental care expenditures. To this end, the study seeks to examine if factors, such as income level or employment-based private health insurance, are significant in determining how much is spent on dental care. In addition, our study investigates if private-household dental care spending is a function of educational status, geographical location (province of residence), and age. There is a gap in the literature looking at inter-provincial variation in dental demand and hence we included province of residence as one of the variables in all the models. This paper presents the factors associated with dental care spending through the use of three models. The first model estimates the income elasticity of demand for dental care and the other two models examine the share of total household income spent on dental care.

\section{Methods}

The 2009 cycle of Survey of Household Spending published by Statistics Canada (2012) was used to analyze dental expenditures in Canada. The survey consists of 10,881 participants. It is representative of $98 \%$ of the population in the ten provinces and nearly $92 \%$ of the population in the Yukon, the Northwest Territories and Nunavut (YTN) (Statistics Canada, 2012).

\subsection{Variables}

The variables of interest were province of residence (PRO), total household income (INC), and presence of private health insurance (INS). Control variables used in our models include demographic information (DEM) of the person interviewed in the household (age, sex, marital status, education, rural residence), total number of full time employed workers in the household (FT) and total household size (HS) (see table 1). The variables were selected based on existing literature (Grytten, Holst, \& Skau, 2012; Quinonez \& Grootendorst, 2011; Manski, Macek, \& Moeller, 2002). There was a gap in the literature looking at inter-provincial variation in dental demand.

\subsection{Regression Analyses}

All the analyses were conducted using Stata/ $/ C^{\mathrm{TM}}$ Version 12.1 and the level of significance was set at 0.05 . The demand for dental care in Canada was assessed using three different models: linear regression, logistic regression and multinomial regression. Different regression techniques were used in order to answer three separate research questions. First, the linear model was used to estimate the income elasticity of Canadians with respect to dental care. Second, the logistic model was used to identify the factors that predict the demand for dental care in Canada. Third, the multinomial model was used to identify the subsets within the Canadian population who were more or less likely to have higher or lower burden of dental expenditure on their income.

\subsection{The Models}

The first model is a linear regression model, which is based on the work of Grytten et al. (2012), to measure the income elasticity of Canadian households with respect to demand for dental care. Therefore, log of dental expenditure (LnDent) was used as a function of the $\log$ of total household expenditure (LnIncome) after controlling for PRO, INS, DEM, HS and FT variables (see table 1 for reference). We use the log-log format in order to interpret the results as elasticity, which is standard in economic analyses:

$$
\text { LnDent }=F(\text { LnIncome, PRO, INS, DEM, HS, FT) }
$$

The second model is a logistic regression model used to examine the usage of dental care using the INC, PRO, INS, DEM, HS, FT variables (see table 1 for reference), where $p$ is the probability of spending anything at all on dental care:

$$
\operatorname{Ln}\left(\frac{p}{1-p}\right)=F(I N C, P R O, I N S, D E M, H S, F T)
$$

The third model is a multinomial regression investigating the burden of dental expenditure as a budget share of the total household income (Dentshare). Dentshare is categorized into three levels: 
i. [0\%] of total household income spent on dental care (no burden category);

ii. $(0 \%-1 \%)$ of total household income spent on dental care (lower burden category);

iii. $[1 \%-100 \%]$ of total household income spent on dental care (higher burden category).

Table 1. Variables in the three dental demand models

\begin{tabular}{|c|c|c|}
\hline Variables & Levels & Definitions \\
\hline \multicolumn{3}{|l|}{ Dental Care Spending (See Note 1) } \\
\hline LnDent & & Natural log of dental expenditure \\
\hline \multirow[t]{3}{*}{ Dentshare } & {$[0 \%]$} & No burden \\
\hline & $(0 \%-1 \%)$ & Lower burden dental expenditure \\
\hline & {$[1 \%-100 \%]$} & Higher burden dental expenditure \\
\hline Insurance (INS) & & Private Health insurance (See Note 2) \\
\hline \multirow[t]{5}{*}{ Total Household Income (INC) } & $\$ 26,000$ or less & Lowest Income bracket \\
\hline & $\$ 27,000-\$ 46,000$ & Lower-middle income bracket \\
\hline & $\$ 47,000-\$ 69,000$ & Middle income bracket \\
\hline & $\$ 70,000-\$ 100,000$ & Upper-middle income bracket \\
\hline & $\$ 100,000<$ & Highest income bracket \\
\hline LnIncome & & Natural log of total household income \\
\hline \multirow[t]{10}{*}{ Provinces (PRO) } & Newfoundland \& Labrador (NFLD) & \\
\hline & Nova Scotia (NS) & \\
\hline & New Brunswick (NB) & \\
\hline & Quebec (QB) & \\
\hline & Ontario $(\mathrm{ON})$ & \\
\hline & Manitoba (MN) & \\
\hline & Saskatchewan (SK) & \\
\hline & Alberta (AB) & \\
\hline & British Columbia (BC) & \\
\hline & Yukon, Territories, Nunavut (YTN) & \\
\hline Employment (FT) & & $\begin{array}{l}\text { Total number of full time employed } \\
\text { workers in the household }\end{array}$ \\
\hline Household size (HS) & & Total Household Size \\
\hline \multicolumn{3}{|l|}{ Demographic Information (DEM) } \\
\hline \multirow[t]{5}{*}{ Age } & 65 and older & Oldest age category \\
\hline & $50-64$ years & Oldest-baby boomers \\
\hline & $40-49$ years & Youngest baby boomers \\
\hline & $30-39$ years & Middle age category \\
\hline & $<29$ years & Youngest age category \\
\hline Sex & Male or Female & \\
\hline Rural Residence & Yes or No & \\
\hline \multirow[t]{3}{*}{ Marital Status } & Married or common law & \\
\hline & Never married (single) & \\
\hline & Other & \\
\hline \multirow[t]{7}{*}{ Education } & \multicolumn{2}{|c|}{ University degree, certificate or diploma above a Bachelor's } \\
\hline & \multicolumn{2}{|c|}{ Bachelor's degree (B.A., B.Sc., B.Ed) } \\
\hline & \multicolumn{2}{|c|}{ University certificate or diploma below Bachelor's } \\
\hline & \multicolumn{2}{|c|}{ Community college, CEGEP or nursing school diploma } \\
\hline & \multicolumn{2}{|c|}{ Apprenticeship certificate Trade/vocational certificate } \\
\hline & \multicolumn{2}{|c|}{ Secondary (high) school diploma or equivalent } \\
\hline & \multicolumn{2}{|c|}{ No degrees, certificates or diplomas } \\
\hline
\end{tabular}

The categorization of Dentshare was based on the distribution of the variable where level I, II and III represent $52.1 \%, 34.0 \%$ and $13.9 \%$ of the population, respectively. 


\subsection{Model Diagnostics}

The first (linear) model (assessing income elasticity) was assessed for outliers. The second model (logistic regression) model was assessed for outliers using standardized Pearson's residuals and the linear predictions. The third model (multinomial model) was assessed for outliers by identifying outliers in the three associated logit models. Variables were tested for a multicolinearity violation using Variation Inflation Factor (VIF).

\section{Results}

In 2009, the average household dental care spending in Canada was approximately $\$ 347.52 .1 \%$ (95\% CI: $51.1 \%-53.0 \%$ ) of the households in Canada had no OOP dental expense. $34.0 \%$ (95\% CI: 33.1\%-34.9\%) of the households spent somewhere between $0 \%$ and $1 \%$ of their income on dental care. The remaining $13.9 \%$ (95\% CI: $13.3 \%-14.6 \%$ ) of the households spent at least $1 \%$ or more of their income on dental care (see appendix for the detailed distribution).

Table 2 shows that approximately three quarters (74.9\%) of the lowest income quintile households do not spend on dental care. In addition, we see that as households' incomes increase, the percentage of households that do not spend on dental care decreases, the percentage of households that spend up to $1 \%$ of their income on dental care increases, and the percentage of households that spend $1 \%$ or more of their income on dental care decreases.

Table 2. Dental health spending in Canada by income group

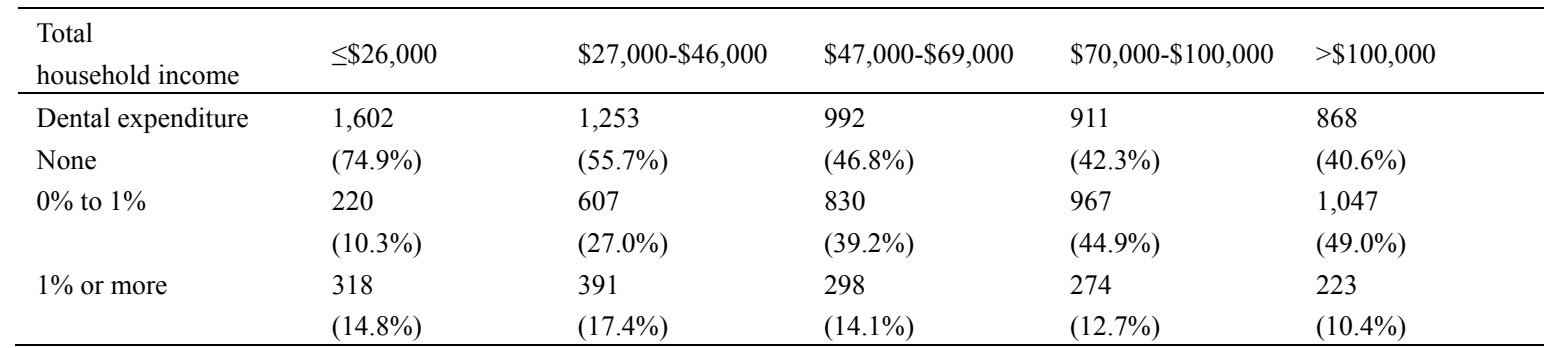

Three models were used to explore the relationships between dental spending and the variables of interest: province of residence, total household income and presence of private insurance controlling for the demographic information of the person interviewed in the household (age, sex, marital status, education, rural residence), total number of full time employed workers in the household and total household size.

The first model (i.e., the linear model) was fit to 4623 ( $89 \%$ of the possible 5228) observations. The sample size in the first model was much smaller than the other two models because $52 \%$ of the overall participants spent $\$ 0$ on dental care-indicating either no use of dental care services or full coverage and therefore could not be assessed for income elasticity. The number of observations in the second (logistic) and third (multinomial) models were fit to $9831(90 \%)$ and 9831 (90\%) observations, respectively.

\subsection{Total Household Income}

The first linear model indicates that the income elasticity of Canadian households in 2009 with respect to dental care spending was 0.146 , indicating a positive relationship between income and dental spending. Our estimated income elasticity (0.146) is somewhat low but consistent with literature from the late 1980s and early 1990s (income elasticity less than 0.10) (Grytten, Holst, \& Skau, 2012). Our estimate suggests that while consumers' demand for dental services is influenced by household income, it is not very responsive to changes in income. In microeconomics terms, this means that dental services in Canada are regarded as a normal necessity good with an elasticity of less than one.

In the second model, we examine which households are most likely to spend $\$ 0$ on dental care. Households that have the highest odds to spend $\$ 0$ on dental care are most likely to be in the lowest income quintile followed by the highest income bracket (see Table 3). This may be due to a multitude of factors including low rates of utilization of dental care by the lowest income households (Grytten, Holst, \& Skau, 2012; Locker, Maggirias, \& Quinonez, 2011) or the presence of supplemental government insurance for lowest income quintile (Federal, Provincial and Territorial Dental Working Group, 2012). Those in the high-income quintile are likely to have better dental health and therefore requiring dental care less or not at all (Costa, Haddad, \& Abreu, 2012; Divaris, Fisher, Shugars, \& White, 2012; Brennan, Spencer, \& Roberts-Thomson, 2011). They are also most likely to have better private insurance coverage, which could mean that they may not have to pay anything for dental care 
at the point of use.

The interesting result from the second model is that the middle-income brackets have the highest odds for spending \$1 or more on dental care (odds ratios of 3.054, 2.966 and 2.561 for middle, lower-middle and upper-middle brackets, respectively, with the associated $p<0.05$ ). Spending $\$ 1$ or more on dental care could be a proxy for the utilization of dental care with a certain type of coinsurance plan. The type of coinsurance plan does affect the utilization of dental care, where low costing plans lead to more utilization (Sadeghi, 2012). However, Sadeghi (2012) indicates that middle income families have lower rates of private dental insurance compared to the previous decade and thus our study shows the demand for dental care is still high among middle income families, even though the rates of private dental insurance have declined.

Our third model shows that the lower income brackets are more likely to be in the higher burden category (see table 4). This finding indicates that among the households that demanded dental care in 2009, the lower income bracket households had a higher burden of dental care spending as a share of overall income. This could be explained by the fact that lower income households suffer from poorer dental conditions (Costa, Haddad, \& Abreu, 2012; Divaris, Fisher, Shugars, \& White, 2012; Brennan, Spencer, \& Roberts-Thomson, 2011) and are much less likely to private health insurance coverage. Thus in spite of the protective effect of supplementary insurance for the lowest income households, lower income families are still likely to face a higher burden of dental expenditure (RRR 8.958, $\mathrm{p}<0.0001$ ). In addition, our study confirms that middle income families still demand more dental care and face higher burden of dental expenditure (compared to the highest income bracket). The result from this model indicate that middle income households face a higher burden of dental spending compared to high income households, which is not surprising since middle income households are more likely to have poorer dental conditions and less likely to have private health insurance as indicated by previous research findings confirming that middle income households have lower rates of private dental insurance compared to a decade ago (Sadeghi, 2012; Costa, Haddad, \& Abreu, 2012; Brennan, Spencer, \& Roberts-Thomson, 2011; Divaris, Fisher, Shugars, \& White, 2012).

Table 3. The odds ratios of spending $\$ 1$ or more on dental care in Canada versus spending $\$ 0$ (controlling for household size, rural residence, number of full time employed workers in the household and province of residence)

\begin{tabular}{llll}
\hline Predictor Variables & Odds Ratio & Predictor Variables & Odds Ratio \\
\hline Income & & Age & \\
$\$ 100,000<$ & $1.937^{*}$ & 65 and older & $1.96^{*}$ \\
$\$ 70,000-\$ 100,000$ & $2.561^{*}$ & $50-64$ years & $1.50^{*}$ \\
$\$ 47,000-\$ 69,000$ & $3.054^{*}$ & $40-49$ years & $1.40^{*}$ \\
$\$ 27,000-\$ 46,000$ & $2.966^{*}$ & Education & \\
Female & $1.12^{*}$ & University-above Bachelor's & $2.27^{*}$ \\
Private Health Insurance & $1.54^{*}$ & Bachelor's degree & $2.39^{*}$ \\
& & University cert. or diploma & $1.98^{*}$ \\
\hline
\end{tabular}

Note. Income: $\$ 26,000$ or more; Sex: Male; Private Health Insurance: No; Age category: $<29$ years; Education: No degrees, certificates or diplomas. ${ }^{*}$-value $<0.05$.

Table 4. The relative risk ratios of Canadian households being in the higher burden versus those households in the lower burden (controlling for household size, rural residence, number of full time employed workers in the household and province of residence)

\begin{tabular}{llll}
\hline Predictor Variables & RRR & Predictor Variables & RRR \\
\hline Income & & Age & \\
$\$ 26,000$ or less & $8.958^{*}$ & 65 and older & $2.550^{*}$ \\
$\$ 27,000-\$ 46,000$ & $3.844^{*}$ & $50-64$ years & $1.781^{*}$ \\
$\$ 47,000-\$ 69,000$ & $2.227^{*}$ & $40-49$ years & $1.633^{*}$ \\
$\$ 70,000-\$ 100,000$ & $1.535^{*}$ & Education & 1.328 \\
Female & 0.993 & University-above Bachelor's & $1.357^{*}$ \\
Private Health Insurance & $0.838^{*}$ & Bachelor's degree & $1.663^{*}$ \\
\hline
\end{tabular}

Note. Income: $>\$ 100,000$; Sex: Male; Private Health Insurance: No; Age category: <29 years; Education: No degrees, certificates or diplomas. *p-value $<0.05$. 


\subsection{Private Health Insurance}

According to our first model, households with private health insurance spend fewer dollars on dental expenditures compared to households with no private health insurance. This makes sense because the purpose of insurance is to have less burden of expenditure on the household. This also raises the alarming issue that there has been a decrease in private health dental insurance in the past decade among middle class families in Canada (Sadeghi, 2012).

According to our second model, the odds to spend a $\$ 1$ or more on dental care is $54 \%$ (p-value $<0.001$ ) more in households with private health insurance compared to those households with no insurance (see table 3). In other words, households with no private health insurance are more likely to spend $\$ 0$ on dental expenditure. Since spending $\$ 1$ or more on dental expenditure is a proxy for dental care utilization, we see that households with private health insurance are more likely to utilize dental care. This result is consistent with recent studies that have shown dental insurance coverage is one of the many factors that determine whether Canadian seek dental care services or not (Millar \& Locker, 1999; Health Canada, 2010; Bhatti, Rana, \& Grootendorst, 2007).

Our third model confirms the findings of our first model by showing that households with higher burden of dental expenditure are $16 \%$ less likely to have private health insurance relative to those households that do have private health insurance (see Table 4). In other words, households with private health insurance are more likely to be in the lower burden category.

\subsection{Demographic Control Variable-Age}

In all three models, there was a statistically significant positive association between age and spending indicating that upper age categories spend more on dental care (see Table 3 and 4). That is, older adults (65 years or older), compared to younger adults (aged 29 years or less) are more likely to spend on dental care, have the highest odds to spend a $\$ 1$ or more $(\mathrm{OR} 1.96$, p-value $<0.001)$ and most likely to be in the higher burden category (RRR 2.55 compared to lower burden category, p-value $<0.001$ ). Research shows that older adults from 60-79 years of age have more root cavities (43\%) than adults 20 to 39 years of age (6\%) (Health Canada, 2010). In addition, recent research has shown that older adults have three times the dental expenditure than the younger population, which is consistent with our results (Grytten, Holst, \& Skau, 2012). Lastly, there is no public dental coverage for elderly population (with the exception of AB and YTN) and the social assistance programs have particular restrictions depending on the provinces (Federal, Provincial and Territorial Dental Working Group, 2012). The social assistance programs are structured to provide emergency care only (Quiñonez et al., 2005).

Another age trend we see is that the "baby boomer" age groups (40-49 years and 50-64 years categories) demand more dental care than the younger adults (see Table 3 and 4). This is interesting because the baby boomers, representing a large portion of the population will be entering the older adult age category in the next two decades.

\subsection{Demographic Control Variable-Education}

Our study looked at the education level of the reference person being interviewed at the household. We find that higher education levels are correlated to an increase in the demand of dental care (see Table 3). This result is consistent with previous studies where adults with less formal education were more likely to have lower OOP expenditure for dental than adults with higher income or education. Manski (2010) found that adults with less formal education or lower income were more likely to have lower out-of-pocket (OOP) expenditures for dental care and services than adults with more education or higher income.

Educational attainment is strongly related to income as highly educated people earn more than less educated people (Carnevale, Rose, \& Cheah, 2011). Our earlier discussion showed that income is related to oral health and thus education is one of the determinants of oral health as well. It is also believed that the more education an individual attains in life, the more he/she is predisposed to information regarding certain health related behaviours like healthy eating, dental check-ups, and physical activity (Grossman, 1972a; 1972b). This increased awareness elevates the individual's need to pursue and undergo dental health services in order to improve his/her oral health, thus spending more money. Our findings confirm the results from previous studies regarding the relationship between an individual's dental care spending and the level of his/her educational attainment.

\subsection{Provinces}

Saskatchewan was used as the reference category for the rest of the provinces. From our linear model, Yukon, Northwest Territories, Nunavut (YTN) and Alberta (AB) households spend the most Out of Pocket (OOP) dental health expenditures whereas Newfoundland \& Labrador (NFLD) and Nova Scotia (NS) households spend the least amount on dental care (Table 5). There was no evidence of statistically significant interprovincial variation 
between Saskatchewan and the following provinces: British Columbia, Manitoba, Ontario, Quebec and New Brunswick.

Table 5. Interprovincial variation

\begin{tabular}{llll}
\hline Provinces & $\begin{array}{l}\text { Likelihood to Spend \$ } \\
\text { (First Model) }\end{array}$ & $\begin{array}{l}\text { \$1 or more VS \$0 } \\
\text { (Second Model) }\end{array}$ & $\begin{array}{l}\text { Higher } \\
\text { Lower Burden }\end{array}$ \\
\hline NFLD vs SK & $-0.280^{*}$ & 1.038 & $0.609^{*}$ \\
NS vs SK & $-0.387^{*}$ & $1.765^{*}$ & $0.557^{*}$ \\
NB vs SK & -0.129 & $2.036^{*}$ & $0.704^{*}$ \\
QB vs SK & -0.0165 & $1.751^{*}$ & 0.762 \\
ON vs SK & -0.0916 & $1.435^{*}$ & 1.159 \\
MB vs SK & -0.0596 & $1.406^{*}$ & 0.788 \\
AB vs SK & $0.281^{*}$ & $1.224^{*}$ & 1.163 \\
BC vs SK & 0.124 & $1.538^{*}$ & 1.089 \\
YTN vs SK & $0.341^{*}$ & $0.572^{*}$ & 1.225 \\
\hline
\end{tabular}

The second model, testing the odds ratios of households spending $\geq \$ 1$ on dental care compared to households spending \$0, shows that YTN households have the highest odds to spend \$0 on dental care (because it has the lowest odds ratio of 0.572 to spend a $\$ 1$ or more). However, our first model showed YTN households spend the most on dental care. Therefore, households that do spend on dental care in YTN pay the highest OOP on dental care. We know that Nunavut (one of the regions of YTN) has had the highest growth in dental expenditure from the public sector (77.6\% with almost $\$ 350$ person) (CCPA, 2011). The growth in public sector expenditures on dental care may explain the high odds of YTN residences of spending $\$ 0$ on dental care. However, many other factors need to be considered including demographics and cost of living; thus this trend needs further investigation.

The demand for dental care is further explored using our third model. Here the demand for dental care is divided into two categories: lower burden and higher burden OOP dental expenditures. The third category is having no burden (spend $\$ 0$ ).

Our third model indicates that the Atlantic Provinces (NFLD, NS, NB) were the least likely to be in the higher burden category (RRRs of $0.609,0.557$ and 0.704 , respectively and p-values are $<0.05$ ) when compared to the other Canadian provinces. There was no interprovincial variation among the other Canadian provinces. Therefore, the non-Atlantic provinces have the same likelihood to have households with higher burden of drug OOP expenditures. Our results are lead to the question, "Why do we see such trends?" The Province variable is a loaded factor that may account for many things including culture, difference in government policies, and cost of living which all could not be controlled for in our study due to data limitations.

\section{Limitations}

Lack of information regarding dental utilization and dental outcomes limit our ability to expand on the interpretations of the study results. The dataset employed in this study does not capture this information and therefore we did not explore issues of dental care utilization and outcomes. The no burden category ( $\$ 0$ spent on dental expenditure) may represent the subset of the population that do not spend on dental care and also those that have excellent dental care insurance coverage.

\section{Discussion}

The income elasticity of demand for dental health care is positive and small, which is consistent with previous studies (Grytten, Holst, \& Skau, 2012). This qualifies dental care as a normal necessity good with a positive elasticity of less than one. Our study shows that lower income families were more likely to not spend on dental care -which is a proxy for not using dental care- and at the same time more likely to have a higher burden of OOP dental expenditures when they do use dental care. These results show that lower income brackets are facing a higher burden of dental expenditure relative to their income due to reasons that should be further explored through more research. One of the possible reasons is the decline in private dental insurance coverage among middle-income families.

In terms of interprovincial variation, we observe that YTN and AB households are the heavy spenders on dental care. In addition, the Atlantic Provinces are the least likely to have households with higher burden for dental care 
expenditure relative to their income compared to the rest of the provinces. More research is needed to understand these variations. Interprovincial variation could be dependent on differences in the demographics of the provinces, legislative differences, difference in GDP per capita or many other factors. Further research in this area would be able to answer why households in Atlantic Provinces are more protected from higher burden of dental expenditure than other provinces.

Our study was consistent with previous studies indicating that OOP dental expenditures among older adults were higher than other age groups. We can anticipate a substantial increase in the demand for dental care as the young and older baby boomers move to the oldest bracket in the next two decades. The critical issue raised by our study is that older adults are more likely to face higher burden of dental expenditure and thus policy makers need to have appropriate measurements to face this problem. The projected increase in the demand for dental care in the foreseeable future would require national policies focusing on preventative dental care use and decreasing chronic tooth decay and other oral health problems in order to reduce the burden of dental expenditure among Canadians (Meyerhoefer, Zuvekas, \& Manski, 2014).

Other variables such as presence of private health insurance and education also were in line with previous research. Private health insurance is correlated with an increase in dental care demand. The noteworthy but also expected result from our study was that private health insurance reduces the likelihood of households facing a higher OOP burden of dental expenditures. Thus private health insurance has a protective effect as it reduces the cost for care, but it also increases demand for care. With respect to economic policy implications, universal dental insurance would reduce household costs on dental expenditures; however, it is likely to lead to an increase in utilization rates and possibly total dental care costs. Therefore, the issue of public dental insurance for basic primary dental care is worth debating and exploring. (Kreider, Manski, Moeller, \& Pepper, 2014).

Future studies to investigate underlying reasons for interprovincial variation in household expenditure on dental care would be prudent. In addition, projected increase in dental care demand due to demographic changes in Canada requires further debate on universal dental insurance for basic primary dental care services and on how preventative dental measures may reduce dental expenditure burden on Canadian households.

Our study examined the burden of Out of Pocket dental expenditure faced by Canadian households. We found that there are disparities and inequities associated with the demand for dental care, which point to the need for further research to develop innovative policy solutions addressing these inequities.

\section{References}

Bhatti, T., Rana, Z., \& Grootendorst, P. (2007). Dental insurance, income and the use of dental care in Canada. Journal of Canadian Dental Association, 73(1), 57. Retrieved from http://www.ncbi.nlm.nih.gov/pubmed/17295945

Brennan, D., Spencer, A., \& Roberts-Thomson, K. (2011). Dental self-care and visiting behaviour in relation to social inequality in caries experience. Community Dental Health, 28(3), 216-221.

Canadian Dental Association. (2010). Dental Health Services in Canada: Facts and Figures 2010. Canadian Dental Association. Retrieved from http://www.med.uottawa.ca/sim/data/Dental/Dental_Health_Services_in_Canada_June_2010.pdf

Carnevale, A., Rose, S., \& Cheah, B. (2011). The College Payoff: Education, Occupations, Lifetime Earnings. The Georgetown University Center on Education and the Workforce. Retrieved from http://cew.georgetown.edu/collegepayoff

CCPA. (2011). Putting our money where our mouth is: the future of dental care in Canada. Ottawa, ON: Canadian Centre for Policy Alternatives. Retrieved from https://www.policyalternatives.ca/publications/reports/putting-our-money-where-our-mouth

CIHI. (2012). National Health Expenditure Trends: 1975 to 2012. Canadian Institute for Health Information. Retrieved from https://secure.cihi.ca/free_products/NHEXTrendsReport2012EN.pdf

Costa, S. V., Haddad, J., \& Abreu, M. (2012). The severity of dental caries in adults aged 35 to 44 years residing in the metropolitan area of a large city in Brazil: a cross-sectional study. BMC Oral Health, 12(25). http://dx.doi.org/10.1186/1472-6831-12-25

Divaris, K., Fisher, E., Shugars, D., \& White, R. J. (2012). Risk factors for third molar occlusal caries: a longitudinal clinical investigation. Journal of Oral \& Maxillofacial Surgery, 1771-1780. http://dx.doi.org/10.1016/j.joms.2011.12.035

Federal Provincial and Territorial Dental Working Group. (2012). Access to Dental Care. Retrieved from 
http://www.fptdwg.ca/English/e-access.html

Grossman, M. (1972). On the concept of Health Capital and the Demand for Health. Journal of Political Economy, 80(2), 223-255. http://dx.doi.org/10.1086/259880

Grossman, M. (1972). The Demand for Health: A Theoretical and Emperical Investigation, New York. National Bureau of Economic Research, 11(4), 1417-1419. Retrieved from http://papers.nber.org/books/gros72-1

Grytten, J., Holst, D., \& Skau, I. (2012). Demand for and utilization of dental services according to household income in the adult population in Norway. Community Dent Oral Epidemiol, (40), $297-305$. http://dx.doi.org/10.1111/j.1600-0528.2011.00659.x

Health Canada. (2010). Summary report on the findings of the oral health component of the Canadian Health Measures Survey: 2007-2009. Retrieved from http://www.fptdwg.ca/assets/PDF/CHMS/CHMS-E-summ.pdf

Kreider, B., Manski, R. J., Moeller, J., \& Pepper, J. (2014). The Effect of Dental Insurance on the Use of Dental Care for Older Adults: A Partial Identification Analysis. Health Econ. http://dx.doi.org/10.1002/hec.3064

Locker, D., \& Millar, W. J. (1999). Dental insurance and use of dental services 1996-1997 data. Health Reports, 11(1), 55-67(Eng). Retrieved from http://www.ncbi.nlm.nih.gov/pubmed/11965824

Locker, D., Maggirias, J., \& Quinonez, C. (2011). Income, dental insurance coverage, and financial barriers to dental care among Canadian adults. Journal of Public Health Dentistry, 71(4), $327-334$. http://dx.doi.org/10.1111/j.1752-7325.2011.00277.x

Manski, R. (2010). Dental care expenditures and retirement. J Public Health Dent, 70(2), $148-155$. http://dx.doi.org/10.1111/j.1752-7325.2009.00156.x

Manski, R., Macek, M., \& Moeller, J. (2002). Private dental coverage: who has it and how does it influence dental visits and expenditures? J. Am Dent Assoc, 133(11), 1551-1559. http://dx.doi.org/10.14219/jada.archive.2002.0087

Meyerhoefer, C. D., Zuvekas, S. H., \& Manski, R. (2014). The Demand for Preventative and Restorative Dental Services. Health Econ, 23, 14-32. http://dx.doi.org/10.1002/hec.2899

Quinonez, C., \& Grootendorst, P. (2011). Equity in dental care among Canadian households. Int J Equity Health, 10(14). http://dx.doi.org/10.1186/1475-9276-10-14

Quiñonez, C., Locker, D., Sherret, L., Grootendorst, P., Azarpazhooh, A., \& Figueiredo, R. (2005). An environmental scan of publicly financed dental care in Canada. Toronto, ON. (A Report). Retrieved from http://www.fptdwg.ca/assets/PDF/Environmental_Scan.pdf

Sadeghi, L. (2012). Trends in Access to Dental Care among Middle-Class Canadians. Dental Public Health Graduate Department of Dentistry University of Toronto, Canada. Retrieved from https://tspace.library.utoronto.ca/bitstream/1807/32276/5/Sadeghi_Laleh_20123_MSc_thesis.pdf

Statistics Canada. (2012). Survey of Household Spending, 2009. Retrieved from http://www.statcan.gc.ca/dai-quo/index-eng.htm

\section{Notes}

Note 1. Dental care spending was defined as direct costs borne by household for dental services and orthodontic and periodontal procedures, including "examinations, cleanings, fillings, extractions, x-rays, root canals, the prescription and fitting of dentures" (Statistics Canada, 2012).

Note 2. Private health insurance spending was defined as direct costs for premiums for private health insurance plans and premiums for dental plans sold as separate policies (Statistics Canada, 2012). 


\section{Appendix A}

The Frequency and Proportions of Households in Canada that Spend Certain Percentage of Their Income on Dental Care

\begin{tabular}{ccc}
\hline $\begin{array}{c}\text { Percentage of household income spent } \\
\text { on dental care }\end{array}$ & Frequency & Proportions (n=10,801) \\
\hline $0 \%$ & 5,626 & $52.1 \%$ \\
$0.1 \%-0.9 \%$ & 3,671 & $34.0 \%$ \\
$1 \%$ or more & 1,504 & $13.9 \%$ \\
$1.0 \%-1.9 \%$ & 718 & $6.6 \%$ \\
$2.0 \%-2.9 \%$ & 283 & $2.6 \%$ \\
$3.0 \%-3.9 \%$ & 169 & $1.6 \%$ \\
$4.0 \%-4.9 \%$ & 96 & $0.89 \%$ \\
$5.0 \%-6.9 \%$ & 93 & $0.86 \%$ \\
$7.0 \%-9.9 \%$ & 70 & $0.65 \%$ \\
$10 \%-19.9 \%$ & 54 & $0.50 \%$ \\
$20 \%$ or more & 21 & $0.19 \%$ \\
\hline
\end{tabular}

\section{Copyrights}

Copyright for this article is retained by the author(s), with first publication rights granted to the journal.

This is an open-access article distributed under the terms and conditions of the Creative Commons Attribution license (http://creativecommons.org/licenses/by/3.0/). 